\title{
Ultrastructure of a haplosporidian containing Rickettsiae, associated with mortalities among cultured paua Haliotis iris
}

\author{
P. M. Hine ${ }^{1, *}$, S. Wakefield ${ }^{2}$, B. K. Diggles ${ }^{1}$, V. L. Webb ${ }^{1}$, E. W. Maas ${ }^{1}$ \\ ${ }^{1}$ National Institute of Water and Atmospheric Research, PO Box 14-901, Kilbirnie, Wellington, New Zealand \\ ${ }^{2}$ School of Medicine, University of Otago, Wellington Hospital, Private Bag 7902, Wellington South, New Zealand
}

\begin{abstract}
Uninucleate and multinucleate stages of a protozoan parasite are described from cultured abalone Haliotis iris Martyn, 1784 in New Zealand. The parasite is identified as a haplosporidian by the occurrence of multinucleate plasmodia, mitochondria with tubular cristae, lipid droplets, anastomosing endoplasmic reticulum (aER), multivesicular bodies (MVBs), haplosporogenesis by the production of haplosporosome-like bodies from nuclear membrane-bound Golgi, and their maturation to haplosporosomes. Coated pits occurred in the plasma membrane and coated vesicles were scattered in the cytoplasm, particularly in association with the Golgi face away from the nucleus, and aER. It is concluded that the outward face of the Golgi may be the trans face, and that aER is the trans-Golgi network. Coated pits and bristle-coated vesicles are reported from a haplosporidian for the first time. The vesicles in the MVBs resembled the cores and inner membranes of haplosporosomes, without the outer layer. The possible inter-relationships of these features are discussed. The abalone parasite differs from previously described haplosporidians in the apparent absence of a persistent mitotic spindle, and the presence of intracytoplasmic coccoid to rod-shaped bacteria resembling Rickettsiales-like prokaryotes. Phylogenetic analysis of the 16S rRNA gene sequence of the Rickettsiales-like prokaryotes indicated that these organisms belong to the Rickettsia cluster. The prokaryotes have a high $(7 \%)$ sequence divergence from known Rickettsieae, with Rickettsia sp. and R. massiliae being the closest relatives. The lack of non-molecular evidence prevents us from proposing a new rickettsial genus at this time.
\end{abstract}

KEY WORDS: Haplosporidian · Intracellular Rickettsiales · Abalone · Haliotis iris · Ultrastructure · Haplosporosomes

Resale or republication not permitted without written consent of the publisher

\section{INTRODUCTION}

Relatively few parasites and diseases have been reported from abalone Haliotis spp., but this may reflect the lack of studies on them, and the recent advent of farming in many countries. Since the early 1980s, epizootic mortalities have been observed in hatcheries of Japanese black abalone Nordotis discus discus, associated with amyotrophia (Nakatsugawa et al. 1988, 1999, Nakatsugawa 1990, Otsu \& Sasaki 1997). The disease is associated with tumour-

${ }^{*}$ Present address: National Centre for Disease Investigation, MAF Operations, PO Box 40-742, Upper Hutt, New Zealand. E-mail: hinem@maf.govt.nz like masses in the nerve trunks of pedal ganglia (Nakatsugawa et al. 1988, 1999), from which cytoplasmic virions $~ 100 \mathrm{~nm}$ in diameter (Otsu \& Sasaki 1997) and icosahedral extracellular virions $120 \mathrm{~nm}$ in diameter (Nakatsugawa et al. 1999), have been reported. However, the $120 \mathrm{~nm}$ virus did not produce the disease when inoculated into healthy abalone, and the identity of these viruses and their role in the disease remain unclear. A similar disease occurs in abalone Haliotis discus hannai in China, but the cause is unknown (Guo et al. 1999).

In the mid-1980s, wild populations of the black abalone Haliotis cracherodii began to decline in southern California (Alstatt et al. 1996), and mortalities were linked to a disease causing atrophy of pedal musculature, epipodial discolouration and diminished 
response to tactile stimuli (Vanblaricom et al. 1993). The disease, which spread to central California (Alstatt et al. 1996) and more recently into farmed red abalone H. rufescens (Moore et al. 1999), is caused by the rickettsial prokaryote (Gardner et al. 1995) Candidatus Xenohaliotis californiensis (Friedman et al. 2000).

The only disease reported from abalone Haliotis spp. in New Zealand has been a shell disease in wild abalone with a fungal aetiology (Grindley et al. 1998). Farming of the abalone (locally called paua) $H$. iris is in its infancy in New Zealand, with about 30 farms scattered around the country. Some farms spawn broodstock and then sell spat on to other farms for on-growing, using commercial feeds. In April 2000, one farm in the eastern Bay of Plenty experienced mortality rates that were well above normal. Samples collected for histology showed the systemic presence of large numbers of uni- to multinucleate plasmodia associated with severe tissue damage. Runts were more severely affected than larger abalone. The former showed only weak adherence to the glass-fibre raceways, a shrivelled foot with pale blister-like lesions of the foot and mantle, and the inability to right themselves when turned over.

This paper describes the ultrastructure of the parasite found in New Zealand abalone, and discusses its affinities, and how it may be involved in pathogenesis. The paper also examines the phylogenetic affiliation of the Rickettsiales-like prokaryotes associated with the haplosporidian using sequence data generated to the 16S rRNA gene, with comparisons made to databases through the BLAST programme (Altschul et al. 1997). This study is complementary to a study on the histopathology of infection by Diggles et al. (2002).

\section{MATERIALS AND METHODS}

Paua Haliotis iris Martyn, $1784(\mathrm{n}=6)$, with a mean length of $27.8 \mathrm{~mm}$ (range 15.0 to $52.5 \mathrm{~mm}$ ), that were sluggish, could not right themselves, could not adhere well to the surface, or which had pale lesions in the foot, were selected for electron microscopy. Each abalone was quickly cut into $\sim 5 \mathrm{~mm}^{3}$ pieces, and immediately placed in $2.5 \% \mathrm{OsO}_{4}$ buffered with $0.22 \mu \mathrm{m}$ filtered seawater (FSW); they were then quickly cut into $\sim 1 \mathrm{~mm}^{3}$ pieces, fixed for $2 \mathrm{~h}$ at $18^{\circ} \mathrm{C}$, rinsed twice in FSW, and stored in FSW for 1 wk. Organelle interrelationships were studied using the zinc iodideosmium tetroxide (ZIO) technique (Pellegrino de Iraldi 1977). Tissues were fixed in $2.5 \%$ glutaraldehyde made up with FSW for $1 \mathrm{~h}$ at $18^{\circ} \mathrm{C}$, washed in FSW, and processed as described by Benchimol \& de Souza (1985). Control grids were incubated for 30 min at $18^{\circ} \mathrm{C}$ with $1 \mathrm{mM}$ dithiotreitol dissolved in $0.1 \mathrm{M}$ Tris buffer
(pH 6.8) before ZIO incubation (Benchimol \& de Souza 1985). Acid phosphatase was demonstrated using $\beta$-glycerophosphatase as a substrate (Robinson \& Karnovsky 1983). Tissues were fixed for $1 \mathrm{~h}$ at $4^{\circ} \mathrm{C}$ in $2 \%$ glutaraldehyde, washed twice in FSW, incubated for $30 \mathrm{~min}$ at $37^{\circ} \mathrm{C}$ in Gomori medium (1 $\mathrm{mM} \beta$-glycerophosphate, $2 \mathrm{mM}$ cerium chloride, $5 \%$ sucrose, $0.1 \mathrm{M}$ $\mathrm{Na}$ acetate-HCL buffer [pH 5.0]); the medium was then changed and the tissue incubated for a further $30 \mathrm{~min}$ and post-incubation washed with $0.1 \mathrm{M} \mathrm{Na}$ cacodylate buffer with $5 \%$ sucrose.

DNA extraction. Total DNA was extracted from a small amount of infected foot and mantle tissue using Proteinase K digestion (Fast Track Invitrogen) at $55^{\circ} \mathrm{C}$ or $2 \mathrm{~h}$ followed by phenol:chloroform extraction (Maniatis et al. 1982) and ethanol precipitation. DNA was quantified using the DyNA Quant 200 system (Hoefer).

Amplification of the 16S rRNA gene. Fifty ng of DNA was amplified using $10 \mu \mathrm{M}$ of each universal primer to the 16S rRNA of bacteria, cyanobacteria and chloroplast 16S rRNA, PB36: AGR GTT TGA TCM TGG CTC AG (Nucleotide Positions 8 to 27 Escherichia coli base-pair numbering) and PB38 GKT ACC TTG TTA CGA CTT; (Nucleotide Positions R1492 to 1508 E. coli base-pair numbering); $\mathrm{MgCl}_{2}$ final concentration $=2.0 \mathrm{mM}_{i} 10 \times$ buffer; $1 \mathrm{mM}$ each of dNTP and 1 U Taq Pol (Boehringer Mannheim). PCR conducted on a Perkin Elmer Cetus had the following profile: $94^{\circ} \mathrm{C}$ for $3 \mathrm{~min}^{2} 25$ cycles of $94^{\circ} \mathrm{C}$ for $55 \mathrm{~s} ; 55^{\circ} \mathrm{C}$ for $45 \mathrm{~s}$; $72^{\circ} \mathrm{C}$ for $1 \mathrm{~min} 30 \mathrm{~s}$. The expected $1500 \mathrm{bp}$ product was visualised following electrophoreses through a $2 \%$ agarose gel and ethidium bromide staining.

The PCR products were purified using the PCR Product Purification Kit (Qaigen) according to the manufacturer's instructions. Purified products were quantified using the DyNA Quant 200 system (Hoefer), to establish DNA concentrations for sequencing reactions. The PCR products from the foot and mantle were submitted for sequencing.

Phylogeny analysis of cloned 16S rDNA sequence. Sequences were initially aligned using BioEdit (available at: www.mbio.ncsu.edu.RnaseP/info/programs/ BIOEDIT/bioedit.html) and the Clustal W programme (within BioEdit), and were determined to be identical to each other or unique. Sequences were compared to the compilation of 16S rRNA gene sequences available in databases using NCIB/BLAST (Altschul et al. 1997) to determine the highest similarity to GenBank and EMBL database sequences. The 16S rRNA gene sequence data was aligned with rRNA gene sequences from EMBL/GenBank using evolutionary conserved primary sequence and secondary structure (Lane 1991). Evolutionary distances were calculated from sequence pair dissimilarities, and phylogenetic relationships were estimated using neighbour-joining 
with Jukes-Cantor correction (Jukes \& Cantor 1969) and programmes contained in BioEdit. The 16S rDNA sequence determined for the Rickettsiales-like organism (RLO) in the foot in this study has been deposited in the EMBL database under Accession No. AJ319724.

\section{RESULTS}

Only uninucleate forms and multinucleate plasmodia were observed. Parasite and organelle sizes are given in Table 1 . The parasite was usually rounded and contained $<6$ nuclei in sections under the transmission electron microscope, <9 nuclei in $\mathrm{H} \& \mathrm{E}$ stained sections under the light microscope (LM) (Fig. 1), and > 20 nuclei in squash preparations. The nuclei were round to irregular, with a granular nucleolus and, rarely, a little scattered heterochromatin (Fig. 2). A cup-like indentation in the nuclear membrane of some parasites contained dense material, which lay away from the nuclear membrane (Fig. 2). This often occurred at more than one nucleus in a section.

Attached to the nuclear membrane were prominent Golgi-like cisternae (here called nuclear-bound Golgi,

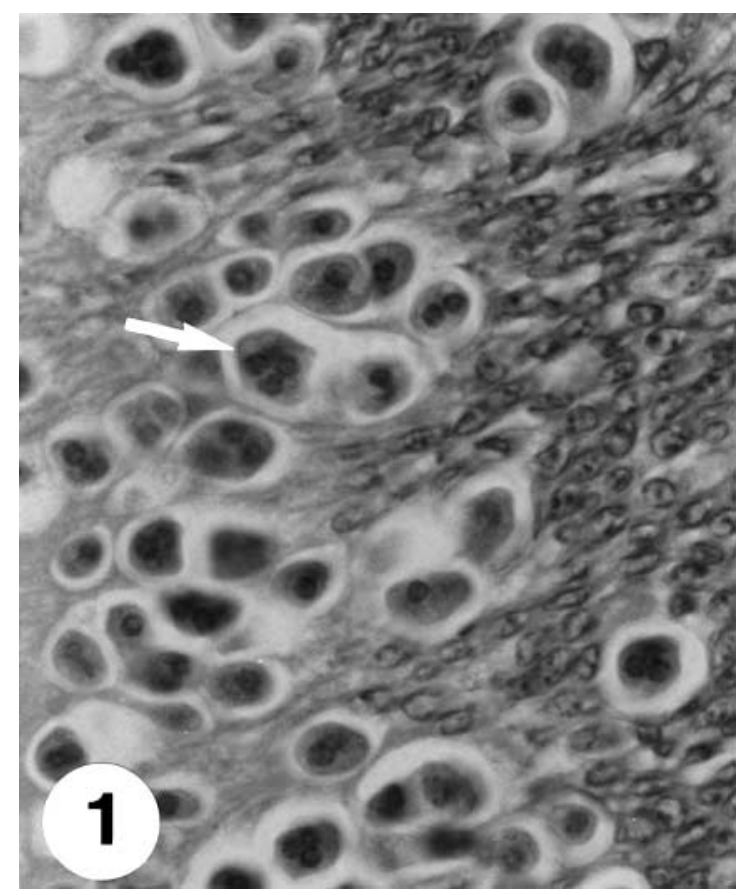

Fig. 1. Haliotis iris. Multinucleate plasmodia in the epithelium of the gut, one of which has 4 nuclei (arrow); $\times 1150$

Table 1. Occurrence and dimensions of organelles in the abalone Haliotis iris parasite. H-LBs: haplosporosome-like bodies; aER: anastomosing endoplasmic reticulum; sER: smooth endoplasmic reticulum; rER: rough endoplasmic reticulum

\begin{tabular}{|c|c|}
\hline Parameter & Dimension \\
\hline Cell size $(\mu \mathrm{m})$ & $5.5-13.5 \times 9.0-4.6$ \\
\hline \multicolumn{2}{|l|}{ Plasma membrance } \\
\hline Coated pits & $3 / 21$ \\
\hline \multicolumn{2}{|l|}{ Nuclei } \\
\hline No. & Live squash preparations $\sim 20$, LM $<6$, TEM $9 \times 1,6 \times 2,4 \times 3,2 \times 4$ \\
\hline Size $(\mu \mathrm{m})$ & $3.6-2.0 \times 3.2-1.7$ \\
\hline Surface depression & $5 / 21$ \\
\hline Microtubules & $0 / 21$ \\
\hline \multicolumn{2}{|l|}{ Cytoplasm } \\
\hline No. of Golgi & $7 \times 0,4 \times 1,3 \times 2,2 \times 3,4 \times 4,1 \times 6$ \\
\hline No. of Golgi stacks & $4.6 \pm 1.2(\mathrm{n}=34)$ \\
\hline Golgi vesicles & In $84 \%$ of Golgi \\
\hline Golgi and H-LBs & In $10.5 \%$ of Golgi \\
\hline Haplosporosome dimensions (nm) & $\begin{array}{l}292-232 \times 160-133,257 \pm 19 \times 150 \pm 7(\mathrm{n}=17) \text {, outer layer 22, membrane 5-8, } \\
\quad \text { core } 102\end{array}$ \\
\hline H-LB dimensions (nm) & 311-200, outer membrane $12-22$, outer layer $15-22$, ring $17-22$, core $102-210$ \\
\hline No. of mitochondria & $8.5 \pm 4.4 /$ section \\
\hline Mitochondrial density & Light 2 , light-moderate 3 , moderate 6 , moderate-dense 1 , dense 9 \\
\hline No. of MVBs & $5.7 \pm 4.0$ \\
\hline Size of MVBs (nm) & $1087-533 \times 1026-430,745 \pm 169(\mathrm{n}=72)$ \\
\hline Vesicle diameter (nm) & 120-144, outer membrane $8-16$ \\
\hline aER & $33 \%$ \\
\hline sER & $95 \%$ \\
\hline rER & 0 \\
\hline No. of lipid droplets & In $33 \%$ of sections, $0.7 \pm 1.2$ \\
\hline Size of lipid droplets $(\mu \mathrm{m})$ & $0.9-2.7 \times 0.4-2.2$ \\
\hline No. of bacteria & $5.6 \pm 4.2$ \\
\hline Size of bacteria (nm) & $882-451 \times 554-388,704 \pm 134 \times 473 \pm 49$ \\
\hline
\end{tabular}




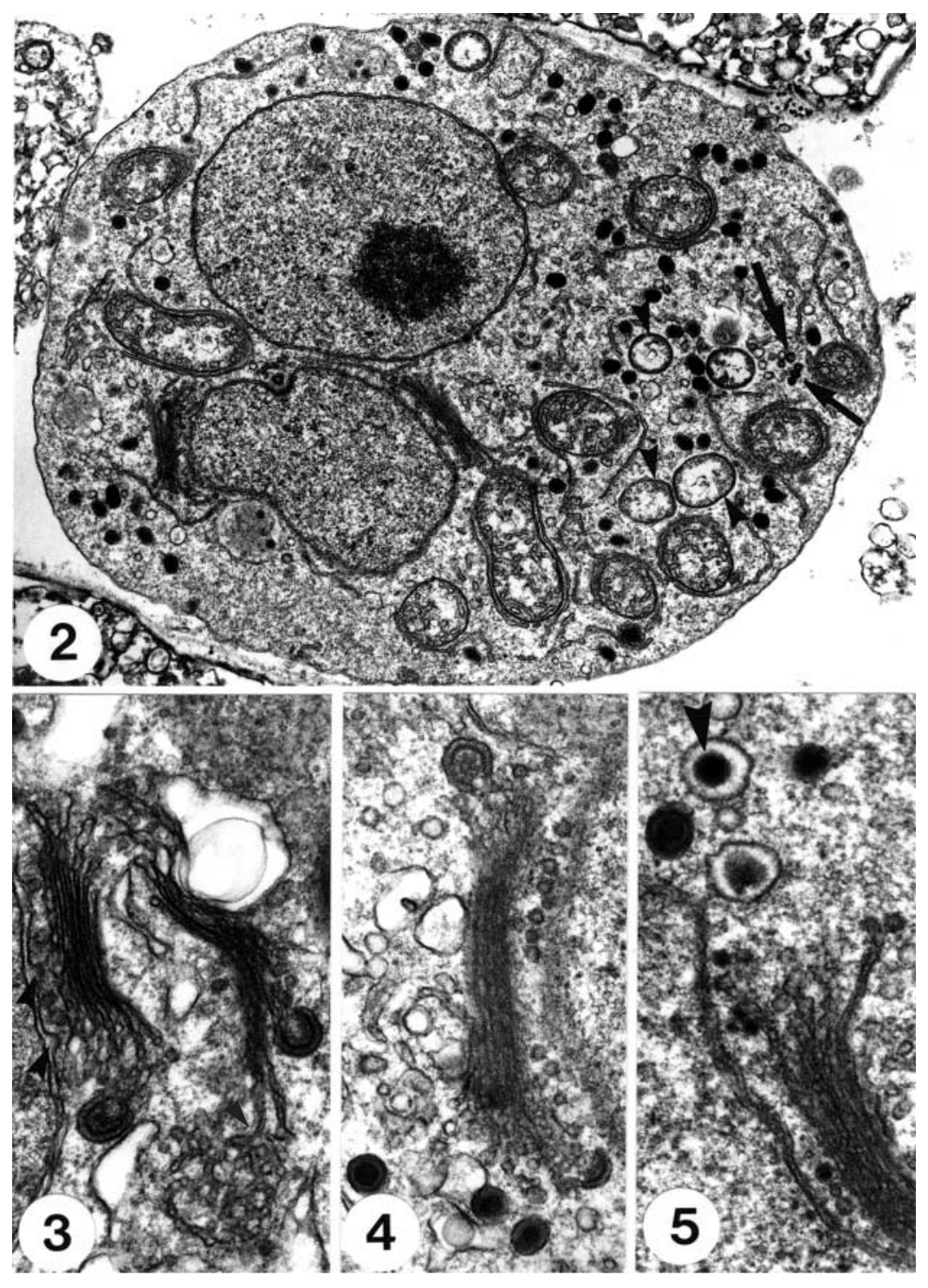

Figs. 2 to 5. Details of nuclear-bound Golgi (NBG). Fig. 2. Section showing 2 nuclei, 1 with a granular nucleolus, 2 NBG, bristle-coated vesicles $\left(\mathrm{BCV}_{\text {; }}\right.$ arrows), mitochondria surrounded by single profiles of smooth endoplasmic reticulum (sER), and intracytoplasmic Rickettsiales-like organisms (RLOs; arrowheads); $\times 12240$. Fig. 3. NBG budding haplosporosome-like bodies (H-LB) connected to anastomosing endoplasmic reticulum $(\mathrm{aER} ; \text { arrow })_{i}$ note vesicles blebbing from the nuclear membrane (arrowhead) $\times 27520$. Fig. 4. Clear vesicles between the nuclear membrane and the cis face of the $\mathrm{NBG}_{i} \times 31550$. Fig. 5. Dense and clear vesicles between the NBG and nuclear membrane, and budding from the NBG; note the similarity in size between the medulla of the haplosporosome and the single vesicle in the multivesicular bodies $(\mathrm{MVB}$; arrowhead) $\times \times 34020$
NBG) comprising 3 to 6 cisternae. Vesicles with a thin coat appeared to bud from the nuclear membrane, and lay between the nuclear membrane and the innermost cisterna (Figs. 3 to 5). Next to the latter lay 2 to 4 cisternae, some of which had a beaded appearance and simple vesicles at 1 or both ends. These cisternae appeared to be connected to anastomosing endoplasmic reticulum (aER; Fig. 3), which sometimes occurred in large arrays (Fig. 6). Frequently, from the end of a cisterna, rose a large ovoid-to-round structure of 2 concentric rings, the innermost of which was thickened (Figs. 3, 4 \& 7), here called haplosporosome-like bodies (H-LBs) (see next paragraph). Close to the outermost cisterna, and budding from it, were bristle-coated vesicles (BCVs; Figs. 7 \& 8), which also occurred throughout the cytoplasm (Fig. 2).
Haplosporogenesis appeared to occur as follows. Granular material occurred in association with osmiophilic material lying in cups on the surface of the nucleus (Figs. $2 \& 12$ ) and with double profiles of endoplasmic reticulum (ER; Fig. 11) lying near to the Golgi where H-LBs were formed at the ends of Golgi cisternae (Figs. 3, 4 \& 7). Stages between H-LBs and haplosporosomes were also frequently observed nearby (Fig. 7). Haplosporosomes, were round-to-ovoid or slightly rod-shaped (Figs. 2, 4, 7 to 9, 10 to 13) with the characteristic internal membrane 5 to $8 \mathrm{~nm}$ across, dividing the organelle into a medulla encircled by the internal membrane, and exterior to that a cortex. In haplosporosomes close to the plasma membrane, the internal membrane became elongated at right angles to the plasma membrane, which they touched (Figs. 10 \& 


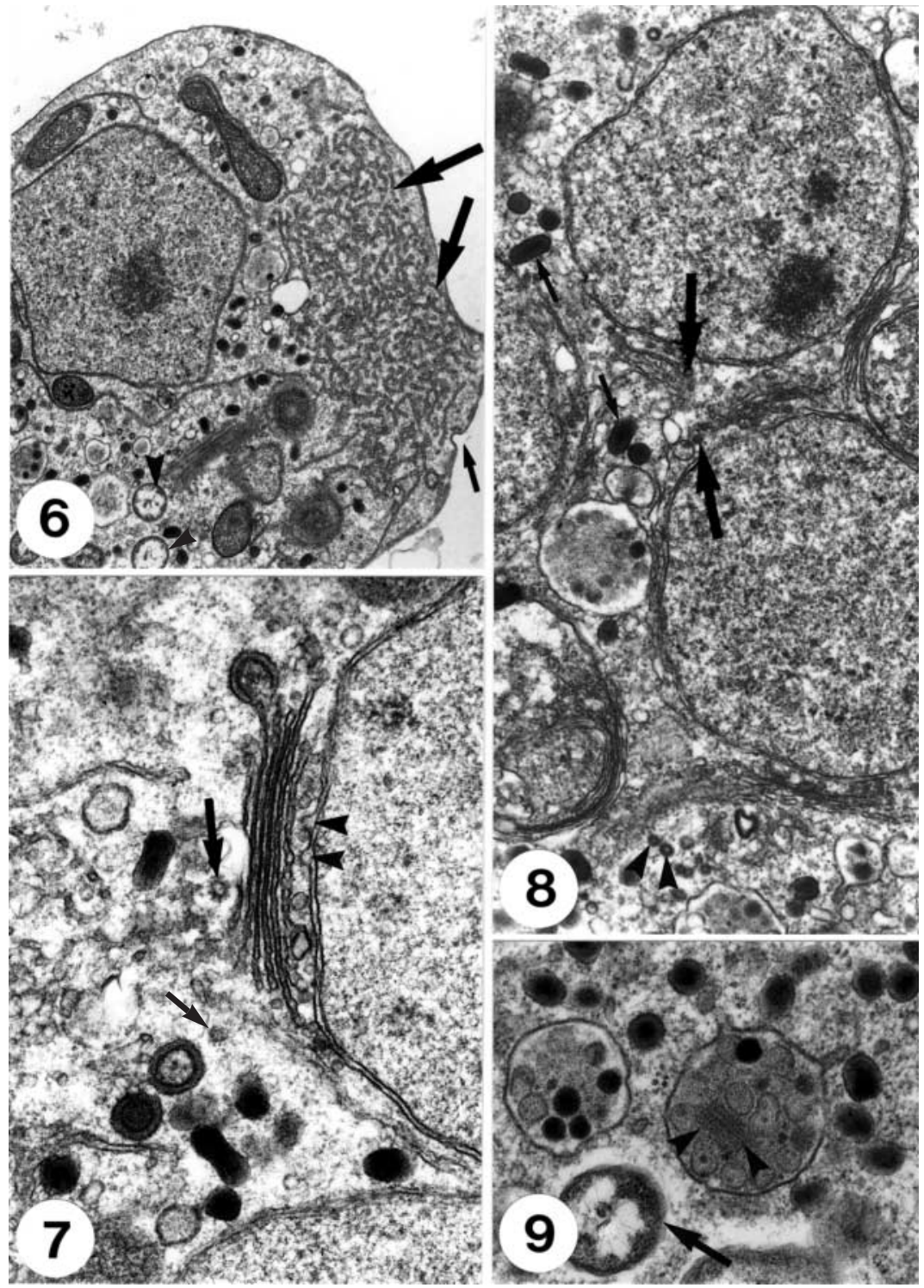

Figs. 6 to 9. Organelles and their relationships. Fig. 6. Section of part of a parasite showing the large arrays of aER (large arrows), a coated pit (small arrow), dense mitochondria, and RLOs (arrowheads); $\times 9910$. Fig. 7. Haplosporogenesis; note vesicles blebbing from the nuclear membrane (arrowheads), H-LBs budding from NBG and lying nearby, BCVs (arrows) and haplosporosomes; $\times 30690$. Fig. 8. NBGs budding BCVs (large

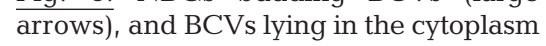
(arrowheads); note elongated haplosporosomes (small arrows) $\times 18110$. Fig. 9. Haplosporosomes, a MVB containing dense and light vesicles and paracrystalline array (arrowheads), and RLO (arrow) $; \times 31020$
12) or appeared to penetrate (Fig. 14). Haplosporosomes or their content may pass through the plasma membrane in a tube-like structure (Fig. 14).

Spherical dense bodies of the same size as the medulla of haplosporosomes were occasionally extracellular or in coated pits on the parasite plasma membrane (Fig. 17). Identical dense bodies, and doublemembraned light vesicles of the same size and shape occurred in multivesicular bodies (MVBs) in the parasite cytoplasm (Figs. 9, 10, 13 \& 14). Some MVBs had tubes extending from them (Fig. 9), but these were not observed to extend to the parasite plasma membrane. Rarely, an elongated haplosporosome appeared to be pushing from the cytoplasm into an MVB (Fig. 15).
The formation of MVBs was unclear, but it appeared that the cortex of a haplosporosome expanded and became less electron dense, leaving the medulla of the haplosporosome (bounded by the internal membrane) in a small vesicle (Figs. 5 \& 11). Flocculent material, possibly from the cortex of the haplosporosome, occurred around the electron-dense membrane-bound medulla (Fig. 11). This was frequently observed, but it would only result in a univesicular body (UVB). How MVBs were then formed is unknown, but possibly by coalescence of UVBs, the direct movement of medullae from the cytoplasm into the MVBs, or movement of vesicles between UVBs and MVBs, possibly through the tubes protruding from the MVBs. In large MVBs, many light vesicles had ruptured membranes, and parallel crystalline structures 


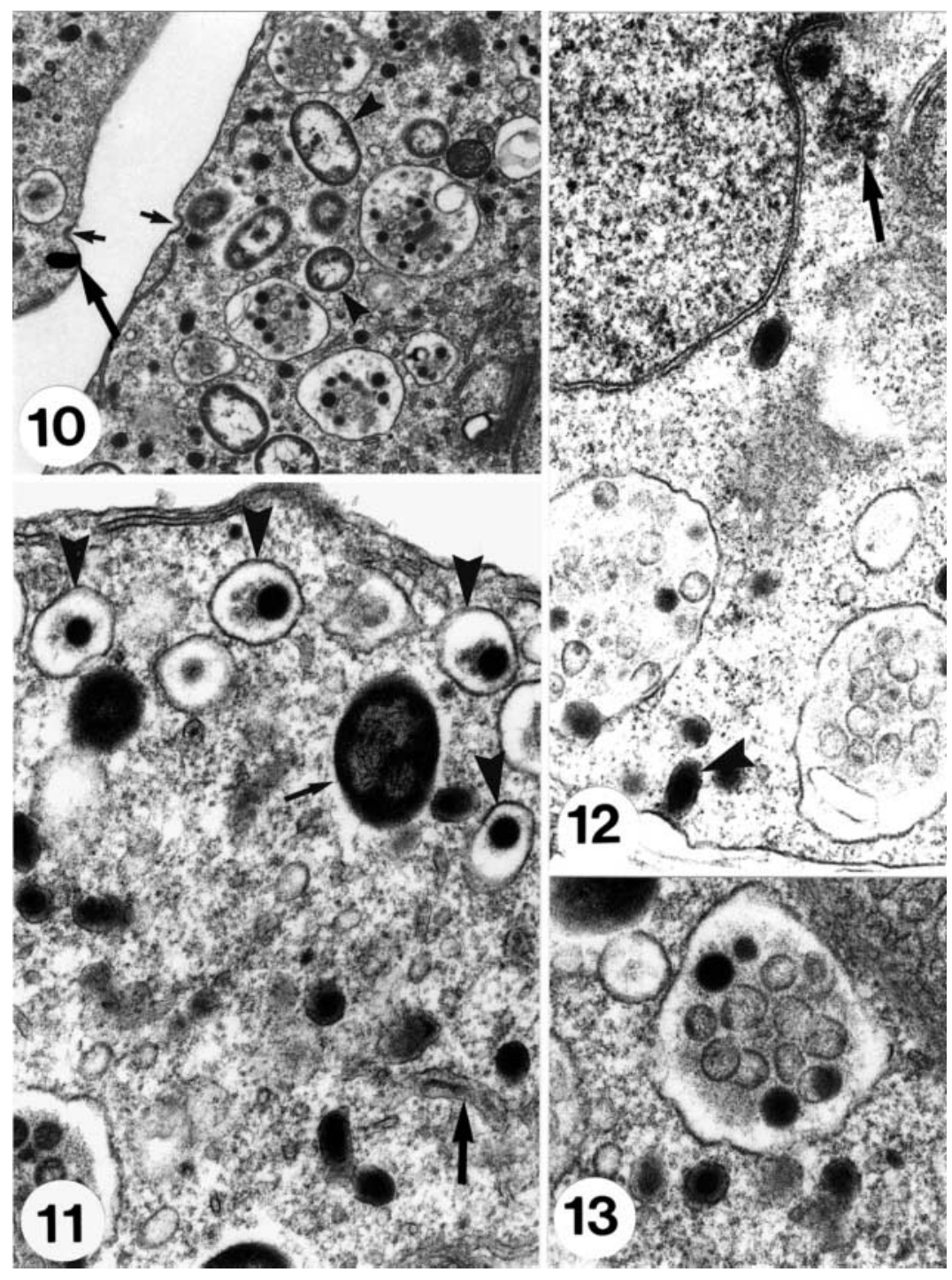

Figs. 10 to 13. Haplosporogenesis and MVBs. Fig. 10. Part of a parasite showing double profiles of ER next to NBG; note also coated pits on the plasma membrane, an elongated haplosporosome touching the plasma membrane (arrow), and RLOs (arrowheads); $\times 13030$. Fig. 11. Parasite cytoplasm with a double profile of ER (large arrow), early MVBs showing single dense vesicles surrounded by flocculent material (arrowheads), and a dense form of (RLO; small arrow); $\times 30060$. Fig. 12. Part of a parasite with a nuclear membrane cup containing dense material, a reticulated granular deposit nearby (arrow), and an elongated haplosporosome touching the plasma membrane (arrowhead); $\times 31600$. Fig. 13. MVB with dense and light vesicles; note the similarity of the vesicle membrane to the internal membrane of the haplosporosome; $\times 40150$ were apparent (Figs. 9, $10 \& 14$ ). Some inclusions, the shape and size of MVBs, contained crystalline lattices (Fig. 18). MVBs were numerous in large degenerating parasites, but were not observed in smaller, apparently healthy, parasites.

Coated pits were common (Figs. 6, $10 \& 17$ ) on the parasite plasma membrane, and numerous putative endocytotic vesicles occurred throughout the cytoplasm (Figs. 6, 10, 11 \& 16). Mitochondria had tubular cristae, varied in density from light (Fig. 2) to very dense (Fig. 6), occasionally contained matrix granules (Fig. 16), and were usually encircled by 1 or more profiles of smooth endoplasmic reticulum (sER) (Figs. 2, 6 \& 16). Ovoid lipid droplets surrounded by strands of sER were occasionally seen in the cytoplasm, and in one case appeared to be endonuclear (Fig. 19).
Ribosomes were common in the cytoplasm, but rough endoplasmic reticulum was not observed.

The ZIO-osmium technique labelled some ER, but not the sER around the mitochondria and lipid droplets. Occasionally the nuclear membrane was labelled (Fig. 20), reaction product sometimes occurred in the small vesicles between the nuclear membrane and the cis-cisterna, and all (Fig. 20), some (Fig. 21), or only the trans-Golgi (Fig. 22) cisternae, were labelled. Vesicles budding from the Golgi (Fig. 21), the cortex of H-LBs deriving from the Golgi cisternae (Fig. 22), and aER near the trans face of the Golgi (Figs. 21 \& 22), usually reacted with the ZIO technique. Within cisternae, the reaction product frequently had a beaded appearance (Fig. 20). ZIO stained cytoplasmic vesicles of irregular size and shape (Figs. $20 \& 21$ ), but not endocytotic 

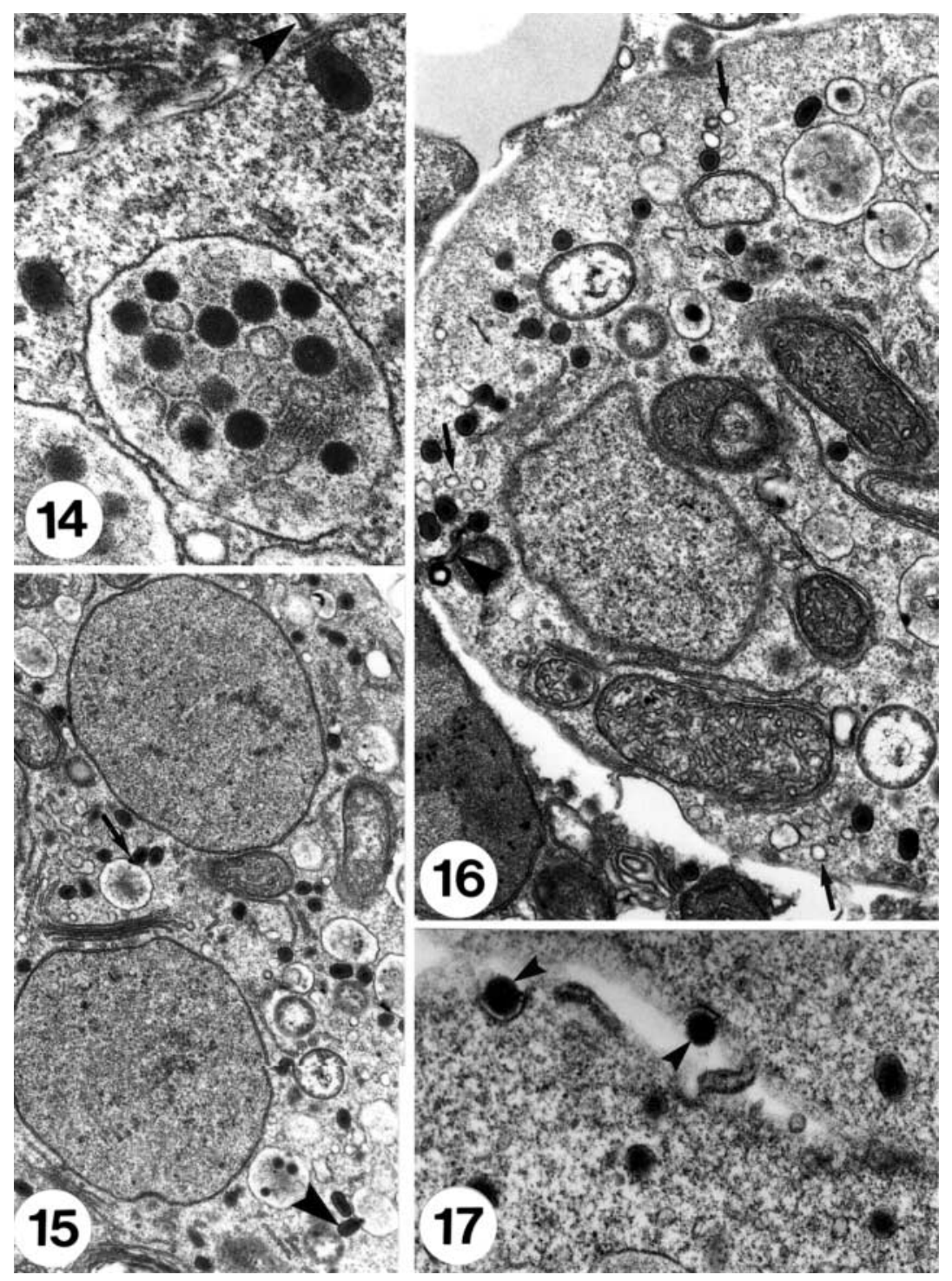

Figs. 14 to 17 . Vesicles and MVB formation. Fig. 14. MVB containing dense and light vesicles and a paracrystalline array; note the haplosporosome apparently penetrating the plasma membrane, and the tube-like structure exterior to the membrane (arrowhead); $\times 41950$. Fig. 15. Part of a parasite showing haplosporosomes touching the membrane of an MVB (arrow), and apparently penetrating an MVB (arrowhead); an unidentified body lies next to the lower nucleus; $\times 11800$. Fig. 16. Parasite cytoplasm with a tube-like structure apparently connecting a haplosporosome to the plasma membrane (arrowhead); note the endocytotic vesicles (arrows) and dense mitochondria with matrix granules; $\times 17280$. Fig. 17. Surfaces of 2 parasites, showing dense vesicles in coated pits on the parasites' surface (arrowheads); $\times 30560$ vesicles, and some membranes within MVBs (Fig. 22), were labelled. Beta-glycerophosphatase labelled Golgi stacks, Golgi vesicles, aER, and some cytoplasmic vacuoles (Fig. 23).

Coccoid to rod-shaped bacteria, often surrounded by a clear space or halo, occurred in the cytoplasm of all parasites, sometimes in chains, and were often abundant. The coccoid appearance was probably due to the plane of sectioning. Their limiting membranes comprised an outer membrane, a periplasmic space and a plasma membrane. Two forms were apparent, one with a light fibrous nucleoid and sparse to moderate marginal ribosomes (Figs. 2, 6, 10 \& 16), and the other with a dense fibrous nucleoid and thick, dense peripheral ribosomes (Fig. 11). Both appeared to occur and divide in chains.
For sequence analysis of PCR-amplified segments, the $5^{\prime}$ terminus of the $16 \mathrm{~S}$ rRNA gene covering variable Region Bases 50 to 787 (Escherichia coli numbering of 16S rRNA gene) was selected. BLAST search showed that both sequences analysed coded for 16S rRNA segments from the family Rickettsiaceae, and more specifically belonging to the spotted fever group (SFG). Within that group, the abalone RLO displayed the highest similarity to Rickettsia sp. and $R$. massiliae (Accession Nos L36102.1 and L36106.1 respectively), both showing $92.8 \%$ similarity. The length of sequences analysed was 700 nucleotides, corresponding to 50 to 787 of the E. coli $16 \mathrm{~S}$ rRNA gene, and contained several hypervariable regions of $16 \mathrm{~S}$ rDNA.

The distance matrix (Table 2) shows that the RLO isolated from the foot and mantle of the abalone are 

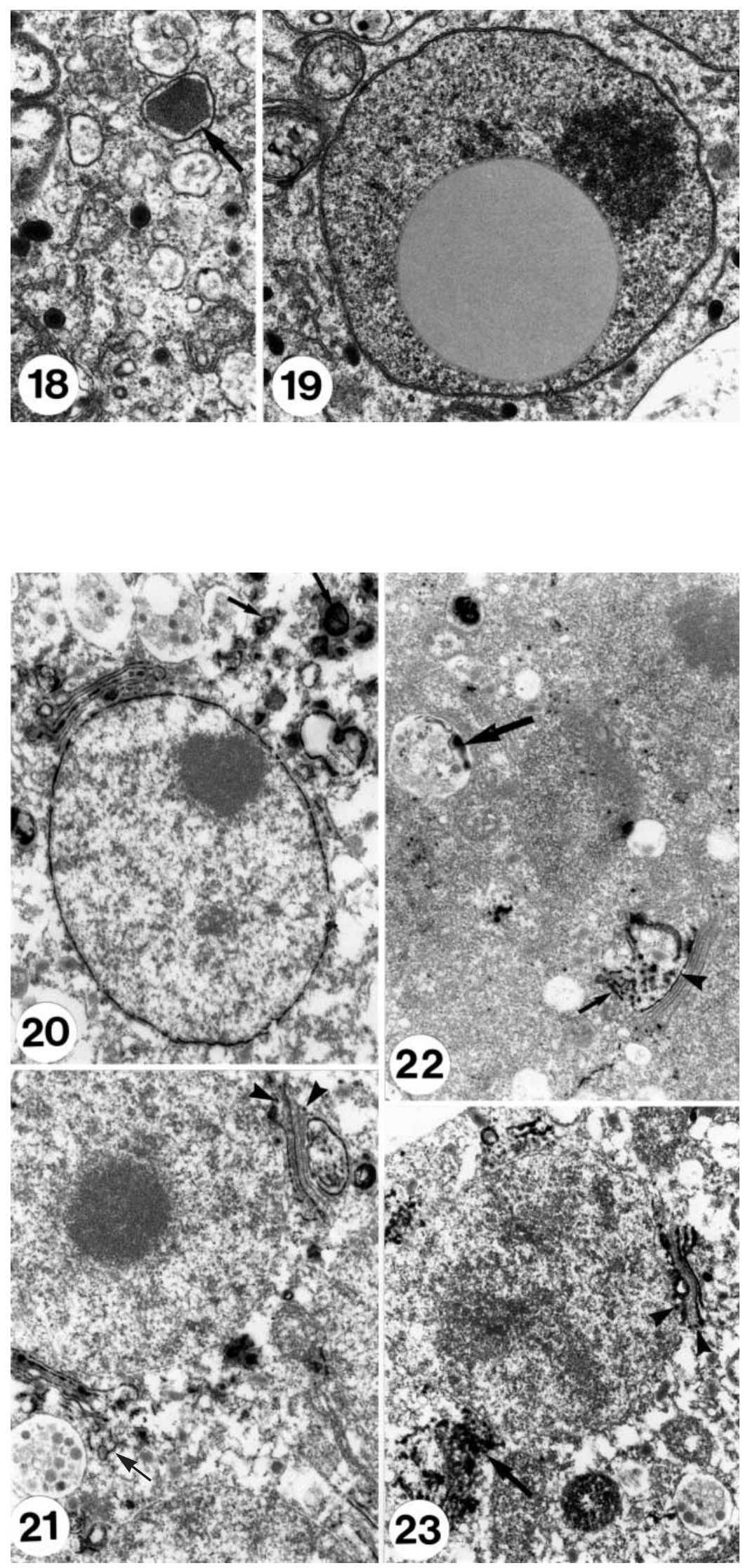

Figs. 18 \& 19. Fig. 18. Intracytoplasmic vesicle containing crystalline array (arrow) $\times 21420$. Fig. 19. Intranuclear lipid droplet $\times 16880$
Figs. 20 to 23. Ultrahistochemistry. Fig. 20. Zinc iodide-osmium tetroxide (ZIO) staining of the nuclear membrane, NBG cisternae and cytoplasmic vesicles varying in size and shape (arrows) $; \times 16580$. Fig. 21. ZIO staining of NBG cisternae, NBG-budded vesicles (arrowheads), aER (arrow), and polymorphic cytoplasmic vesicles; $\times 16440$. Fig. 22. ZIO staining of the trans face of the NBG (arrowhead), aER (small arrow), and membranes inside an MVB (large arrow); $\times 16450$. Fig. 23. Acid phosphatase staining of NBG, NBG vesicles (arrowheads), aER (arrow), and cytoplasmic vacuoles; $\times 16300$ 


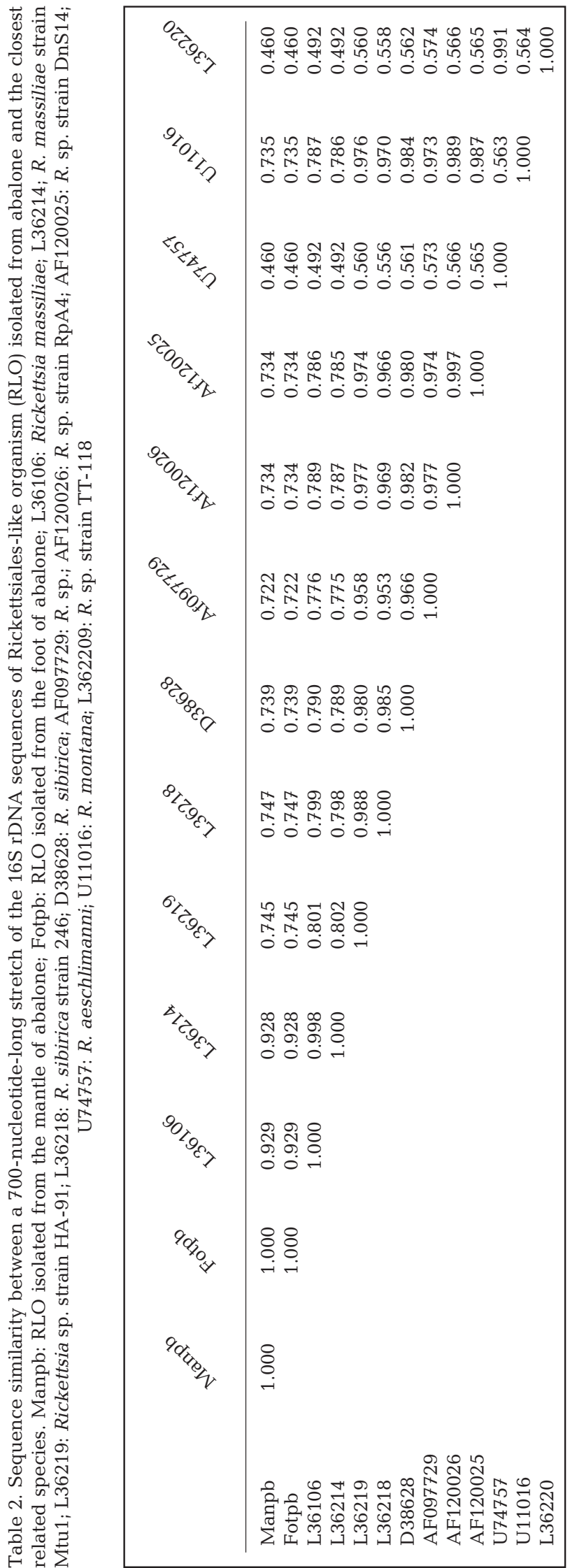

identical over the length of sequence analysed. Analyses were performed using a sequence of 11 of the closest organisms, all of which belong to the genus Rickettsia. The results obtained by using neighbourhood-joining showed similar relationships between the positions of our samples in relation to the clusters of known taxa. The results support placing the organisms in a separate cluster, most probably constituting a new genus within the Rickettsiales.

\section{DISCUSSION}

The features that typify a haplosporidian are currently unclear. Originally, possession of haplosporosomes (after which the group is named) characterized a haplosporidian. However, the groups with haplosporosomes (haplosporidians, paramyxeans, vegetative stages of myxozoans) are not closely related, and myxozoans are metazoans (Smothers et al. 1994), having affinities with the Bilateria (Anderson et al. 1998). Therefore, simple possession of haplosporosomes does not typify the group, and other features have to be considered.

There are currently 4 haplosporidian genera (Haplosporidium, Minchinia, Urosporidium, Bonamia), although Mikrocytos roughleyi is also a haplosporidian (Hine \& Cochennec unpubl. data). Crustacean haplosporidians with haplosporosomes attached to the nuclear membrane, and possibly lacking spores (Newman et al. 1976, Dyková et al. 1988), may represent another genus. Haplosporidium spp., Minchinia spp. and Urosporidium spp. all produce characteristic spores from multinucleate syncytia which derive from multinucleate plasmodia, but spores are unknown from Bonamia spp. and M. roughleyi. Bonamia spp. lack multinucleate syncytia, but multinucleate, possibly tetranucleate, plasmodia have rarely been observed under the light microscope, and $M$. roughleyi has a multinucleate plasmodial stage (Hine \& Cochennec unpubl. data). A diplokaryotic stage, in which the 2 nuclei are joined but may have an internuclear chamber between them, has been reported from species of Haplosporidium (Perkins 1969, 1975a, Marchand \& Sprague 1979), Minchinia (Desportes \& Nashed 1983), and Bonamia (Hine 1991, Hine et al. 2001). Therefore, diplokarya and multinucleate plasmodia may be stages that characterize haplosporidians, and the stages observed in abalone were uninucleate stages to multinucleate plasmodia, but not diplokarya.

Other features of the abalone parasite also resemble those of haplosporidians. The genesis of H-LBs from NBG and their transformation to haplosporosomes is similar to the genesis of haplosporosomes in Bonamia exitiosus (= Bonamia sp.) (Perkins 1979, Hine \& Wesney 
1992, Hine et al. 2001). In B. exitiosus, the material forming the cores of H-LBs derives from cup-like indentations on the nuclear surface, and HLBs are formed at the Golgi in association with confronting cisternae. The presence of similar cup-like indentations in Haplosporidium costale (Fig. 9 in Perkins 1969) suggests a similar process of haplosporogenesis in that species.

The association of sER with the mitochondria has also been reported from haplosporidian plasmodia in Ostrea edulis (Vivarès et al. 1982, Bachère \& Grizel 1983, Bonami et al. 1985). Lipid droplets serve as energy reserves in Haplosporidium spp. (Perkins 1968, 1975a), Minchinia dentali (Desportes \& Nashed 1983), Bonamia exitiosus (Hine 1991, Hine \& Wesney 1994), and the O. edulis haplosporidian (Vivarès et al. 1982, Bonami et al. 1985).

In the abalone, the NBG were more numerous than in Bonamia exitiosus (Hine et al. 2001), but the number of cisternae comprising Golgi in the abalone parasite $(4.6 \pm 1.2)$ was similar to the number in $B$. exitiosus $(4.3 \pm 0.9)$ (Hine \& Wesney 1992, 1994). In the abalone, parasite vesicles were budding from $84 \%$ of the Golgi, unlike the Golgi of $B$. exitiosus, which was not observed to bud vesicles (Hine \& Wesney 1994). The association of the outward face of the NBG with smooth and coated vesicles, the association of the aER with both these vesicles, and the apparent connection between the NBG and the aER suggest that the outward face of the NBG is the trans face, and that the aER may be equivalent to the trans-Golgi network (Becker \& Melkonian 1996). A similar aER has been reported for B. exitiosus (Hine \& Wesney 1994), Haplosporidium costale (Fig. 1 in Perkins 1969) and H. louisiana (Fig. 3 in Perkins 1975a).

The MVBs of the abalone parasite are unlike any reported from haplosporidians, except for a similar structure rarely observed in the cytoplasm of Bonamia exitiosus (Fig. 22 in Hine \& Wesney 1992). In B. exitiosus, the MVBs contain vesicles of varying size and shape, whereas in the abalone parasite they are of uniform size and shape and resemble the medullae of haplosporosomes. In $B$. exitiosus, the MVBs appear to become progressively more dense and haplosporosomes form from them (Figs. 24 \& 25 in Hine \& Wesney 1992), and similar dense MVBs occur in the cytoplasm and are involved in haplosporogenesis in Haplosporidium nelsoni (Perkins 1968, 1979). Although vegetative stages of the myxozoan parasite PKX also form bodies resembling haplosporosomes from the trans-Golgi face, and these bodies are seen in MVBs, the latter are formed when the bodies are engulfed by cup-like structures (Morris et al. 2000), which were not observed here.

There was no suggestion of haplosporogenesis in the abalone parasite MVBs, quite the reverse: MVBs seemed to derive from degenerating haplosporosomes. It also appeared that the medulla of the haplosporosome may penetrate through the plasma membrane to become extracellular, and may then be endocytosed via coated pits. In the MVBs, the dense haplosporosome medullae appeared to rupture their membranes, losing their content to produce light vesicles, and the content then crystallised. This therefore seemed to be a degenerative process.

Whereas $\beta$-glycerophosphatase is known to label the Golgi/lysosome system, it is unclear what ZIO-osmium labels (Pellegrino de Iraldi 1977, Benchimol \& de Souza 1985), although in protozoans it appears to label the nuclear membrane/Golgi/vesicle/lysosome system (Benchimol \& de Souza 1985, Slomianny \& Prensier 1990). In the parabasalid Tritrichomonas foetus, the ZIO-osmium technique labeled the nuclear membrane, and the membranes and cisternae of the Golgi complex (Benchimol \& de Souza 1985). The cisternae and budding vesicles of the trans face were more intensely stained, and some cytoplasmic vacuoles, $0.5 \mu \mathrm{m}$ in diameter, also showed a reaction product (Benchimol \& de Souza 1985).

On the basis of the ultrastructural observations, and bearing in mind the known secretory pathways of protists (Becker \& Melkonian 1996) (particularly apicomplexans with similar NBG; Hager et al. 1999), and the results obtained with the $\beta$-glycerophosphatase and ZIO-osmium techniques, the interpretation of the organelle inter-relationships in the abalone parasite appear to be as follows. The ER, which encircles the mitochondria and lipid droplets, is connected to the nuclear membrane (Palade 1975) from which arise thinly coated vesicles that lie between the nuclear membrane and the cis-cisterna of the Golgi. Similar thinly coated vesicles that arise from the nuclear membrane of Toxoplasma gondii to lie between the membrane and the cis-cisterna are coated with coatomer COP-I and possibly COP-II (Hager et al. 1999), as in mammals (Salama \& Schekman 1995).

The vesicles fuse with the cis-cisterna and proteins are synthesised through the Golgi stacks to the medial and trans-cisternae, where 2 types of vesicle and H-LBs are formed. Firstly, uncoated vesicles arise from medial and possibly trans-cisternae; they enlarge and remain in the cytoplasm. As these vesicles are positive for $\beta$-glycerophosphatase, the intracytoplasmic vesicles are probably primary lysosomes. Secondly, vesicles that are probably clathrin-coated arise from the trans face of the Golgi and these, as in other eukaryotes, probably develop into uncoated secretory vesicles (Becker \& Melkonian 1996). Thirdly, H-LBs form from the medial and possibly trans face cisternae. If haplosporogenesis occurs as in Bonamia sp., H-LBs are formed from the short strands of confronting cisternae 
and the granular material that derives from cup-like indentations in the nuclear surface (Hine \& Wesney 1992).

Haplosporosomes and their homologues occur in phylogenetically distantly related groups, the Haplosporidia, the Paramyxaea, and the Myxozoa. The function of haplosporosomes is unknown; although it has been suggested that they are pre-sporulation energy reserves (Azevedo \& Corral 1985), they may be proto-viruses (Perkins 1971, Hine \& Wesney 1992), or they may be involved in spore wall formation (Ginsburger-Vogel \& Desportes 1979). In the haplosporidian Haplosporidium nelsoni, haplosporosomes align along the plasma membrane with an invagination in the internal membrane orientated at $90^{\circ}$ to the surface (Scro \& Ford 1990), and they disappear in the early stages of sporulation (Perkins 1968), supporting the interpretation that they may be involved in spore wall formation. The similar sporoplasmosomes of PKX, unlike the sporoplasmosomes of other myxozoans (Anderson et al. 1999), have a lucent bar-like invagination and also orientate along the plasma membrane (Morris et al. 2000). However, the PKX organism, Tetracapsula bryosalmonae, also has haplosporosomes (Canning et al. 2000) which do not orientate along the plasma membrane, suggesting that they have an alternative function.

The parasite reported here appeared as uninucleate to multinucleate cells, resembling those of the 4 recognized haplosporidian genera. However, the abalone parasite lacked a persistent intranuclear mitotic spindle, which is an important characteristic of the genera Haplosporidium (Perkins 1968, 1969, 1975b, Marchand \& Sprague 1979), Minchinia (Desportes \& Nashed 1983), Bonamia (Hine 1991) and Urosporidium (Perkins 1971, 1975b).

This is also the first haplosporidian to be reported with intracytoplasmic bacteria. The occurrence of an outer membrane, periplasmic space and plasma membrane indicates that the bacteria are Gram-negative (Beveridge 1999), rod-like in shape, and that they probably divide in chains within the cell and therefore resemble members of the Rickettsiales (Silverman 1991). Phylogenetic analysis of the 16S rRNA gene sequence indicates that the RLOs here are most closely related to Rickettsia massiliae and Rickettsia sp., with $7.2 \%$ sequence divergence identified over the 700 nucleotides analysed. These 2 closest rickettsias, as well as the closet 30 related species identified by the BLAST search, all belong to the spotted fever group (Roux \& Raoult 1995), strongly suggesting that the RLO in this study also belongs to this group. There are however differences between the RLO in this study and other members of the group. Firstly, Roux \& Raoult reported that members of the SFG are found in both the nuclei and the cytoplasm of their hosts. The RLO found in the haplosporidian from abalone were confined to the cytoplasm of the host. Secondly, members of the SFG invariably have an arthropod intermediated host (Roux \& Raoult 1995). Such a host has not yet been identified for the RLO in this study.

The high degree of sequence divergence from other known rickettsias suggests that the organism under study should be assigned to a new genus. The abalone parasite was associated with widespread damage to surrounding host cells to the extent that eventually it replaced all the connective tissue, and normal tissue architecture was only maintained by epithelia and their basement membranes (Diggles et al. 2002). Ultrastructurally, the parasite appeared to be very active metabolically, with many active Golgi cisternae and large numbers of MVBs. This metabolic activity may be linked to the destruction of surrounding cells and the apparently high pathogenicity of this parasite. On the basis of these ultrastructural observations, 2 methods of pathogenicity may have been involved.

Firstly, there was considerable haplosporogenesis: haplosporosomes were occasionally seen at the plasma membrane, uniform vesicles of similar size and shape occurred in coated pits on the plasma membrane, and large numbers of these uniform vesicles occurred in MVBs. One possible interpretation is that haplosporosomes or their contents are exocytosed, they release toxins that destroy surrounding cells, and the remnant haplosporosome core and surrounding membrane are endocytosed into MVBs. A similar mechanism has been proposed for the haplosporosomes of Haplosporidium nelsoni, in which haplosporosomes orientate along the plasma membrane, possibly to discharge a toxin (Scro \& Ford 1990). The haplosporosomes of H. nelsoni also appear to elongate and form a tube-like structure that attaches to the plasma membrane (Fig. 16 in Perkins 1979). The haplosporosomes of $H$. nelsoni also show enlargement and loss of density between the outer and inner membranes (Fig. 15 in Perkins 1979), as observed here, but this occurs in host cells surrounding $H$. nelsoni, not in the parasite itself, as observed here. It is notable that while haplosporosomes occur in disparate protists and cnidarians, they only occur in parasitic groups, not in free-living organisms. A better understanding of the role of haplosporosomes may reveal the mechanisms of pathogenicity in these organisms.

Secondly, the intracytoplasmic RLOs may be involved in parasite pathogenicity. The Haplosporidia are members of the Alveolata, along with apicomplexans, ciliates and dinoflagellates. There is growing evidence that toxin production by some dinoflagellates may be associated with endosymbiotic bacteria (Dantzer \& Levin 1997, Gallacher \& Smith 1999). 
Although rickettsias have not been reported from dinoflagellates, they do occur as endosymbionts in Acanthamoeba spp. (Fritsche et al. 1999), and acanthamoebae with chlamydial and rickettsial endosymbionts show increased pathogenicity (Fritsche et al. 1998). This may be caused by rickettsial-derived lipopolysaccharide (LPS), as filarial nematodes (Brugia malayi) infected by the rickettsia Wolbachia sp., cause elevated inflammatory responses due to Wolbachia sp. LPS (Taylor et al. 2000). However, in general, rickettsias are not thought to express any toxic factor, and their lipopolysaccharides do not have potent toxic activity (Eremeeva et al. 2000).

In conclusion, the parasite of abalone is identified as a haplosporidian, as it occurs as multinucleate plasmodia that show very similar haplosporogenesis to Bonamia exitiosus and other haplosporidians. It differs from previously described genera in the possession of coated pits, bristle-coated vesicles, MVBs, and uniform bodies within the MVBs that resemble the medullae of haplosporosomes, and also in the presence of intracytoplasmic bacteria that belong to the spotted fever group of the Rickettsiaceae.

\section{LITERATURE CITED}

Alstatt JM, Ambrose RF, Engle JM, Haaker PL, Lafferty KD, Raimondi PT (1996) Recent declines of black abalone Haliotis cracherodii on the mainland coast of central California. Mar Ecol Prog Ser 142:185-192

Altschul S, Madden TL, Schaffer AA, Zhang J, Zhang Z, Miller W, Lipman DJ (1997) Gapped BLAST and PSI-BLAST: a new generation of protein database search programs. Nucleic Acids Res 25:3389-3402

Anderson CL, Canning EU, Okamura B (1998) A triploblast origin for Myxozoa? Nature 392:346-347

Anderson CL, Canning EU, Okamura B (1999) Molecular data implicate bryozoans as hosts for PKX (phylum Myxozoa) and identify a clade of bryozoan parasites within the Myxozoa. Parasitology 119:555-561

Azevedo C, Corral L (1985) Cytochemical analysis of the haplosporosomes and vesicle-like droplets of Haplosporidium lusitanicum (Haplosporida, Haplosporidiidae), parasite of Helcion pellucidus (Prosobranchia). J Invertebr Pathol 46: 281-288

Bachère E, Grizel H (1983) Mise en évidence d' Haplosporidium sp. (Haplosporida - Haplosporidiidae) parasite de l'Huître plate Ostrea edulis. Rev Trav Inst Pêches Marit 46: 226-232

Becker B, Melkonian M (1996) The secretory pathway of protists: spatial and functional organization and evolution. Microbiol Rev 60:697-721

Benchimol M, de Souza W (1985) Tritrichomonas foetus: cytochemical visualization of the endoplasmic reticulum-Golgi complex and lipids. Exp Parasitol 59:51-58

Beveridge TJ (1999) Structures of Gram-negative cell walls and their derived membrane vesicles. J Bacteriol 181: 4725-4733

Bonami JR, Vivarès CP, Bréhelin M (1985) Étude d'une nouvelle haplosporidie parasite de l'huître plate Ostrea edulis L.: morphologie et cytologie de différents stades.
Protistologica 21:161-173

Canning EU, Curry A, Feist SW, Longshaw M, Okamura B (2000) A new class and order of myxozoans to accommodate parasites of bryozoans with ultrastructural observations on Tetracapsula bryosalmonae (PKX organism). J Eukaryot Microbiol 47:456-468

Dantzer WR, Levin RE (1997) Bacterial influence on the production of paralytic shellfish toxins by dinoflagellated algae. J Appl Microbiol 83:464-469

Desportes I, Nashed NN (1983) Ultrastructure of sporulation in Minchinia dentali (Arvy), an haplosporean parasite of Dentalium entale (Scaphopoda, Mollusca); taxonomic implications. Protistologica 19:435-460

Diggles BK, Nichol J, Hine PM, Wakefield S, CochennecLaureau N, Roberts RD, Friedman CS (2002) Pathology of cultured paua Haliotis iris Martyn, 1784 infected with a novel haplosporidian parasite, with some observations on the course of disease. Dis Aquat Org (in press)

Dyková I, Lom J, Fajer E (1988) A new haplosporean infecting the hepatopancreas in the penaeid shrimp, Penaeus vannamei. J Fish Dis 11:15-22

Eremeeva ME, Dasch GA, Silverman DJ (2000) Interaction of Rickettsiae with eukaryotic cells. Adhesion, entry, intracellular growth, and host cell responses. Subcell Biochem 33:479-516

Friedman CS, Andree KB, Beauchamp KA, Moore JD, Robbins TT, Shields JD, Hedrick RP (2000) 'Candidatus Xenohaliotis californiensis', a newly described pathogen of abalone, Haliotis spp., along the west coast of North America. Int J Syst Evol Microbiol 50:847-855

Fritsche TR, Sobek D, Gautom RK (1998) Enhancement of in vitro cytopathogenicity by Acanthamoeba following acquisition of bacterial endosymbionts. FEMS Microbiol Lett 166:231-236

Fritsche TR, Horn M, Seyedirashti S, Gautom RK, Schleifer KH, Wagner M (1999) In situ detection of novel bacterial endosymbionts of Acanthamoeba spp. phylogenetically related to members of the order Rickettsiales. Appl Environ Microbiol 65:206-212

Gallacher S, Smith EA (1999) Bacteria and paralytic shellfish toxins. Protist 150:245-255

Gardner GR, Harshbarger JC, Lake JL, Sawyer TK, Price KL, Stephenson MD, Haaker PL, Togstad HA (1995) Association of prokaryotes with symptomatic appearance of withering syndrome in black abalone Haliotis cracherodii. J Invertebr Pathol 66:111-120

Ginsburger-Vogel T, Desportes I (1979) Étude ultrastructurale de la sporulation de Paramarteilia orchestiae gen. n., sp. n., parasite de l'amphipode Orchestia gammarellus (Pallas). J Protozool 26:390-403

Grindley RM, Keogh JA, Friedman CS (1998) Shell lesions in New Zealand Haliotis spp. (Mollusca, Gastropoda). J Shellfish Res 17:805-811

Guo X, Ford SE, Zhang F (1999) Molluscan aquaculture in China. J Shellfish Res 18:19-31

Hager KM, Streipen B, Tilney LG, Roos DS (1999) The nuclear envelope serves as an intermediary between the ER and Golgi complex in the intracellular parasite Toxoplasma gondii. J Cell Sci 112:2631-2638

Hine PM (1991) Ultrastructural observations on the annual infection pattern of Bonamia sp. in flat oysters, Tiostrea chilensis. Dis Aquat Org 11:163-171

Hine PM, Wesney B (1992) Interrelationships of cytoplasmic structures in Bonamia sp. (Haplosporidia) infecting oysters Tiostrea chilensis: an interpretation. Dis Aquat Org 14: $59-68$

Hine PM, Wesney B (1994) The functional cytology of Bonamia 
sp. (Haplosporidia) infecting oysters (Tiostrea chilensis): an ultracytochemical study. Dis Aquat Org 20:207-217

Hine PM, Cochennec-Laureau N, Berthe FCJ (2001) Bonamia exitiosus n. sp. (Haplosporidia) infecting flat oysters Ostrea chilensis in New Zealand. Dis Aquat Org 47:63-72

Jukes T, Cantor CR (1969) Evolution of protein molecules. In: Munro H (ed) Mammalian protein metabolism. Academic Press, New York, p 21-132

Lane DJ (1991) 16S/23S rRNA sequencing. In: Stackebrandt E, Goodfellow M (eds) Nucleic acid techniques in bacterial systematics. John Wiley \& Sons, Chichester, p 115-175

Maniatis T, Fritsch, EF, Sambrook J (1982) Molecular cloning: a laboratory manual. Cold Spring Harbor Laboratory, Cold Spring Harbor, NY

Marchand J, Sprague V (1979) Ultrastructure de Minchinia cadomensis sp.n. (Haplosporida) parasite du décapode Rhithropanopeus harrisii tridentatus Maitland dans le canal de Caen à la mer. J Protozool 26:179-185

Moore JD, Robbins TT, Friedman CS (1999) Withering syndrome in farmed red abalone, Haliotis rufescens. J Shellfish Res 18:319

Morris DJ, Adams A, Richards RH (2000) Observations on the electron-dense bodies of the PKX parasite, agent of proliferative kidney disease in salmonids. Dis Aquat Org 39:201-209

Nakatsugawa $\mathrm{T}$ (1990) Infectious nature of a disease in cultured juvenile abalone with muscular atrophy. Fish Pathol 25:207-211

Natsugawa T, Hatai K, Kubota SS (1988) Histopathological findings on cultured juvenile abalone, Nodortis discus, with muscular atrophy. Fish Pathol 23:203-204

Nakatsugawa T, Nagai T, Hiya K, Nishizawa T, Muroga K (1999) A virus isolated from juvenile Japanese black abalone Nordotis discus discus affected with amyotrophia. Dis Aquat Org 36:159-161

Newman MW, Johnson CA, Pauley G.B (1976) A Minchinialike haplosporidan parasitizing blue crabs, Callinectes sapidus. J Invertebr Pathol 27:311-315

Otsu R, Sasaki K (1997) Virus-like particles detected from juvenile abalones (Nordotis discus discus) reared with an epizootic fatal wasting disease. Dis Aquat Org 70: 167-168

Palade GE (1975) Intracellular aspects of the process of protein transport. Science 189:347-358

Pellegrino de Iraldi A (1977) Significance of the Maillet method (ZIO) for cytochemical study of subcellular structures. Experientia (Basel) 33:1-10

Perkins FO (1968) Fine structure of the oyster pathogen Minchinia nelsoni (Haplosporida, Haplosporidiidae). J Invertebr Pathol 10:287-307

Perkins FO (1969) Electron microscope studies of sporulation in the oyster pathogen, Minchinia costalis (Sporozoa:

Editorial responsibility: Albert Sparks,

Seattle, Washington, USA
Haplosporida). J Parasitol 55:897-920

Perkins FO (1971) Sporulation in the trematode hyperparasite Urosporidium crescens de Turk, 1940 (Haplosporida: Haplosporidiidae) - an electron microscope study. J Parasitol 57:9-23

Perkins FO (1975a) Fine structure of Minchinia sp. (Haplosporida) sporulation in the mud crab, Panopeus herbstii. Mar Fish Rev 37:46-60

Perkins FO (1975b) Fine structure of the haplosporidan KERNSTAB, a persistent, intranuclear mitotic apparatus. J Cell Sci 18:327-346

Perkins FO (1979) Cell structure of shellfish pathogens and hyperparasites in the genera Minchinia, Urosporidium, Haplosporidium, and Marteilia-taxonomic implications. Mar Fish Rev January-February:25-37

Robinson JM, Karnovsky MJ (1983) Ultrastructural localization of several phosphatases with cerium. J Histochem Cytochem 31:1197-1208

Roux V, Raoult D (1995) Phylogenetic analysis of the genus Rickettsia by $16 \mathrm{~S}$ rDNA sequencing. Res Microbiol 146: 385-396

Salama NR, Schekman RW (1995) The role of coat proteins in the biosynthesis of secretory proteins. Curr Opin Cell Biol 7:536-543

Scro RA, Ford SE (1990) An electron microscope study of disease progression in the oyster, Crassostrea virginica, infected with the protozoan parasite, Haplosporidium nelsoni (MSX). In: Perkins FO, Cheng TC (eds) Pathology in marine science. Academic Press, New York, p 229-254

Silverman DJ (1991) Some contributions of electron microscopy to the study of the Rickettsiae. Eur J Epidemiol 7: 200-206

Slomianny C, Prensier G (1990) A cytochemical ultrastructural study of the lysosomal system of different species of malaria parasites. J Protozool 37:465-470

Smothers JF, von Dohlen CD, Smith LH, Spall RD (1994) Molecular evidence that the myxozoan protists are metazoans. Science 265(5179):1719-1721

Taylor MJ, Cross HF, Bilo K (2000) Inflammatory responses induced by the filarial nematode Brugia malayi are mediated by lipopolysaccharide-like activity from endosymbiotic Wolbachia bacteria. J Exp Med 191:1429-1436

Vanblaricom GR, Ruediger JL, Friedman CS, Woodard DD, Hedrick RP (1993) Discovery of withering syndrome among black abalone, Haliotis cracherodii Leach, 1814, populations at San Nicolas Island, California. J Shellfish Res 12:185-188

Vivarès CP, Brehélin M, Cousserans F, Bonami JR (1982) Mise en évidence d'une nouvelle haplosporidie parasite de l'huître plate Ostrea edulis L. CR Acad Sci Sér III Sci Vie 295:127-130

Submitted: August 30, 2001; Accepted: December 14, 2001 Proofs received from author(s): May 24, 2002 